\title{
Fungi in corals: symbiosis or disease? Interaction between polyps and fungi causes pearl-like skeleton biomineralization
}

\author{
T. Le Campion-Alsumard ${ }^{1}$, S. Golubic ${ }^{2}$, K. Priess $^{1}$ \\ ${ }^{1}$ Centre d'Océanologie de Marseille, Université d'Aix Marseille II, URA CNRS 41, Station Marine d'Endoume, \\ F-13007 Marseille, France; and Antenne du Muséum et de l'EPHE, Moorea, BP 1013, French Polynesia \\ ${ }^{2}$ Biological Science Center, Boston University, 5 Cummington Street, Boston, Massachusetts 02215, USA
}

\begin{abstract}
The skeleton of live coral Porites lobata is regularly bored by euendolithic algae (mostly Ostreobium quekettii) and fungi, both commonly extending up to the very tips of newly produced skeletal spines. The live polyp tissue of $P$. lobata occupies a 4 to $5 \mathrm{~mm}$ thick surface layer of the corallum, within which new skeletal material is deposited. Thus, the endoliths do not constitute a separate zone beneath the live polyps; rather, the polyp tissue and populations of endolithic algae and fungi of significant densities co-exist and interact within the same layer. Aragonitic, hemispherical to conical outgrowths protruding from the walls of structural pores were observed in skeletons of $P$. lobata from the barrier reef of Moorea Island, near Tahiti, French Polynesia. These protrusions were always associated with endolithic fungal hyphae attempting to exit from the skeleton into the space occupied by polyps. The polyps responded to such intrusions in a manner similar to the response of mollusks to foreign bodies: by local deposition of dense skeletal material. As the fungus continued to penetrate through this repair deposit, new layers of aragonite were added by the polyp, contributing to the growth of the protrusions. Fungal hyphae rarely entered the pore spaces while these were still occupied by coral polyps. More often, the polyps escaped the fungus by moving upward, as a part of their normal growth rhythm, evacuating the previously occupied skeletal pores. Deprived of resistance, fungal hyphae penetrated through the cones and exited into emptied pore spaces. The conical structures were affected by diagenesis differently than the intact skeletal carbonate. Both skeletal carbonate and repair carbonate were subject to syntaxial diagenetic crystal growth, but they resulted in cements with disparate crystal sizes. Septate fungal hyphae are common in coral skeletons as euendoliths, as cryptoendoliths in structural voids, and as endophytes inside filaments of endolithic algae. They were also found inside soft coral tissue. Fungi may be opportunistic pathogens in corals under environmental stress. Their activity, recorded and preserved in the coral skeleton, provides information on changes in past conditions of coral growth.
\end{abstract}

KEY WORDS: Fungi - Corals · Bioerosion - Endoliths · Euendoliths · Microborers · Diagenesis · Parasitism · Ostreobium · French Polynesia

\section{INTRODUCTION}

Most works on corals concentrate on relationships between coral animals, zooxanthellae and calcification (e.g. Pearse \& Muscatine 1971, Chalker 1983). Less attention is paid to other co-existing organisms, such as phototrophic endolithic algae and heterotrophic fungi that may interact with corals in interrelationships other than symbiosis. Endolithic algae and fungi that penetrate coral skeleton are of particular interest. Low light intensities (Halldal 1968) and low and fluctuating oxygen pressures (Shashar \& Stambler 1992) within coral skeleton render this environment an ecological extreme, which only a few specialized organisms can endure.

The presence of endolithic fungi in mollusk shells has been known for more than a century (Bornet \& Flahault 1889), and a number of papers discuss their taxonomic identity and ecological significance (e.g. Pulicek 1983, Porter \& Lingle 1992, Hook \& Golubic 1993). Less 
information is available on identity, diversity and ecological roles of fungi in corals. Most reports on coral diseases (e.g. Antonius 1981a, b, Goldberg \& Makemson 1981, Rützler et al. 1983, Goldberg et al. 1984) do not include fungi among coral pathogens. It is assumed that their effect on the host is negligible, or that the fungi in corals are saprophytes that exploit dead organic matter incorporated in coral skeletons by the coral or produced by endolithic algae and cyanobacteria (Kendrick et al. 1982).

A successful isolation and culturing of higher, ascomycotic and basidiomycotic fungi from the skeletons of Atlantic and Pacific hermatypic corals (Kendrick et al. 1982) allowed the first identification of fungal genera and species that were likely candidates for the known and widespread coral borers. Kendrick et al. (1982) cultured 20 fungal taxa isolated from coral reefs, documenting the presence and viability of fungal propagules in this marine environment. A similar approach was used by Raghukumar \& Raghukumar (1991), who reported fungi associated with coral necrosis. Both studies reported distribution of fungi inside coral skeleton but did not establish fungal pathogenicity. Bak \& Laane (1987) reported dark discoloration and banding inside coral skeleton caused by fungi. They also called attention to a possible active interaction between corals and fungi.

Various aspects of coral skeletogenesis have been subject to a large number of studies (e.g. Barnes 1970, Johnston 1980, Le Tissier 1990, 1991), but the effects of endolithic organisms that may interfere with normal skeleton formation have rarely been considered. Mechanisms of normal skeletal accretion in corals have been discussed in conjunction with seasonal variation of skeletal density (Barnes 1970, Barnes \& Lough 1993), including rhythmic incremental upward displacement of polyps in Porites lutea (Barnes \& Lough 1992).

The present paper reports on growth of endolithic algae and fungi that occurs within the polyp zone of the hermatypic coral Porites lobata, parallel and concurrent with skeletogenesis. It discusses the spatial and functional interrelationship between endolithic fungi, algae and corals. In addition, it documents a defense response by corals to fungal invasion which leaves a permanent mark in coral skeleton. Finally, differences in early diagenesis between intact and affected coral skeleton are reported.

\section{MATERIALS AND METHODS}

Corals for this study were collected along the Tiahura transect in shallow lagoons at the NW coast of the Pacific volcanic island Moorea, near Tahiti, French Polynesia (Le Campion et al. 1995: this issue). Fragments of the massive corals Porites lobata and P. lutea, including intact surface with underlying skeleton, were collected and fixed in the field with $2.5 \%$ glutaraldehyde in sea water and cacodylate buffer $(20 \mathrm{~h}$, $\mathrm{pH}$ adjusted to 8 ), postfixed in $2 \%$ osmium tetroxide in sea water $(2 \mathrm{~h})$, and then gradually dehydrated in a graded alcohol series. A number of these samples were subsequently critical-point dried and examined under a scanning electron microscope (SEM) to observe the fungi in pore spaces. A second set of samples was transferred into araldite and hardened by polymerization at $60^{\circ} \mathrm{C}$ for $75 \mathrm{~h}$ (Golubic et al. 1970). Petrographic thin sections were prepared perpendicular to the coral surface and examined under a light microscope using transmitted and cross-polarized light. A subset of embedded blocks was cut open and partially or completely etched with $\mathrm{HCl}$ to remove the carbonate substrate and expose the resin casts of euendolith borings, permitting the study of fungi within carbonate substrate.

\section{RESULTS}

\section{Observations: euendolithic fungi and algae in corals}

Euendolithic (sensu Golubic et al. 1981), i.e. microboring, algae and fungi were found throughout the coral skeleton, including the newly deposited skeletal spikes (pali) at the growing front of the coral (Fig. 1).

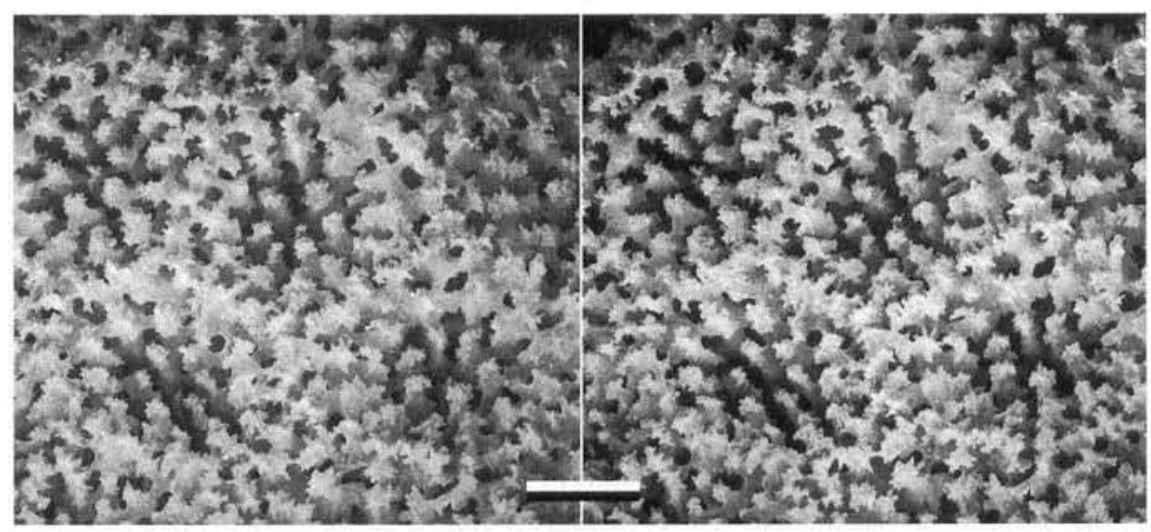

Fig. 1. Porites lobata. Columnar skeleton elements (spikes, or 'pali') built at the growing front by unit polyps of the coral. Each polyp constructs a cup-shaped arrangement of concentrically placed spikes around a central 'columella' which later expand and interconnect laterally by horizontal elements ('synapticules'), seen deeper within the skeleton. SEM stereo-pair; scale bar $=500 \mu \mathrm{m}$ 
Fig. 2. Porites lobata. Endolithic algae and fungi in the skeleton of a live coral. (A) Side view through the tip of a corallum spike, with tunnels of the siphonal chlorophyte Ostreobium quekettii (o). (B) View through a skeletal sliver adjacent to the polyp zone. Surface of the skeleton (s) is in contact with the polyp tissue (dark, osmium-stained). Inside the skeleton are large branched tunnels of $O$. quekettii (o), and much smaller tunnels of fungal hyphae (h). A skeletal protuberance (c) enclosing a thin fungal hypha is seen at the upper left. Light micrographs; same magnification; scale bar $=10 \mu \mathrm{m}$
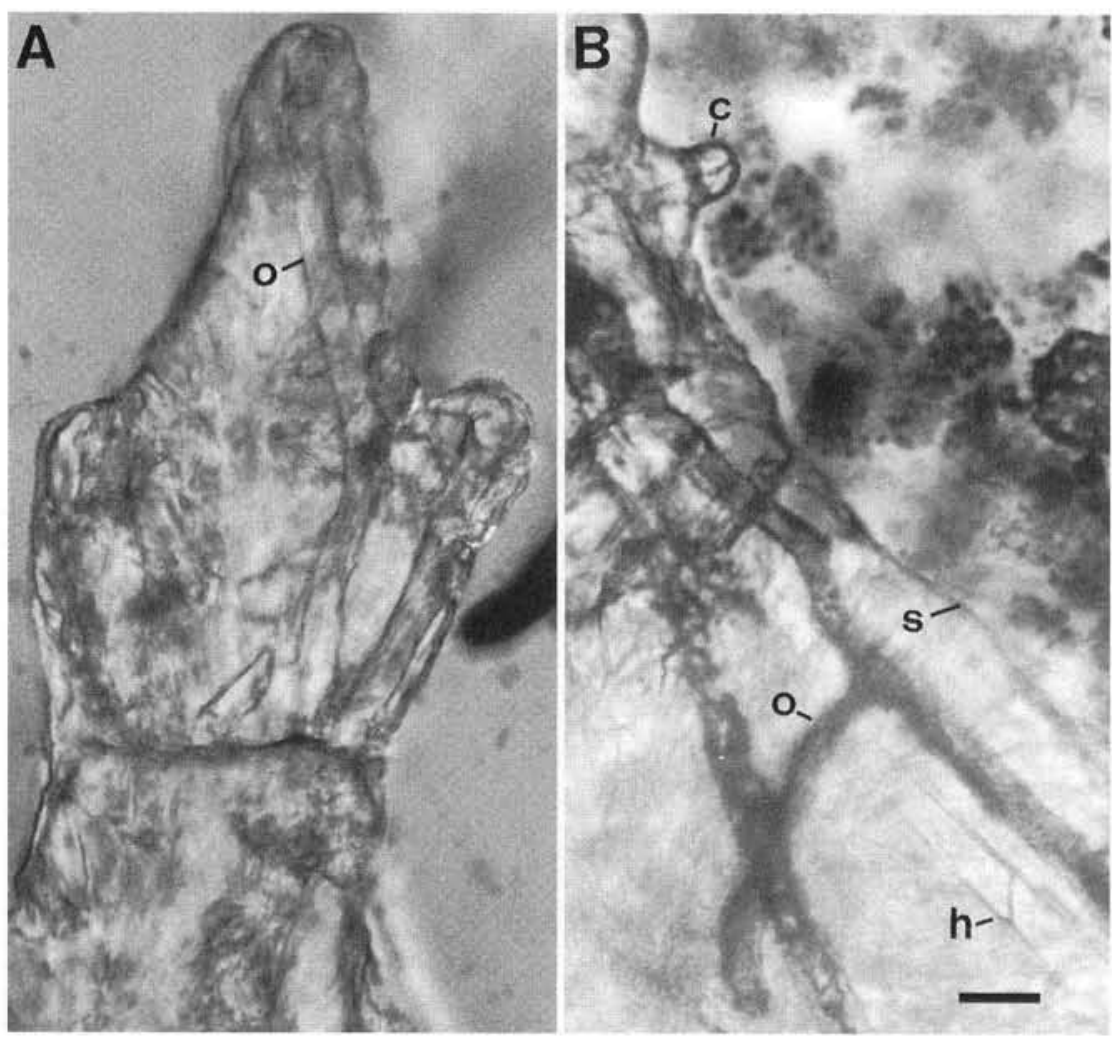

Both endolithic algae and fungi frequently extended all the way to the tips of new spikes (Fig. 2A). Endolith density increased toward the lower end of the polyp zone (Fig. 2B), which in the studied corals varied between 3 and $4 \mathrm{~mm}$. This tendency then continued into the uninhabited portions of the coral skeleton below, often culminating in a colored band (see Le Campion-Alsumard et al. 1995). The endoliths were dominated by the ubiquitous and cosmopolitan siphonal chlorophyte Ostreobium quekettii Bornet et Flahault ('o' in Fig. 2B), accompanied by smaller fungal hyphae ('h'). Fungal hyphae penetrated the carbonate matrix independently of $O$. quekettii, producing their own perforations. However, the same fungi frequently entered $O$. quekettii borings, attacked the alga and continued to grow and branch within algal filaments (Fig. 3A, Bi see also Lukas 1974). The tunnels of $O$. quekettii were variable in diameter, with frequent widening and narrowing of the passages. In the distal portion of the corallum they were 3.5 to $10 \mu \mathrm{m}$ [mean $\pm \mathrm{SD}(\mathrm{n})=5.93 \pm 1.28(37)]$ in diameter. In contrast, the tunnels of fungal hyphae were cylindrical, considerably less variable in diameter, i.e. 1 to $2.2 \mu \mathrm{m}[1.48 \pm 0.27(49)]$, and no more than $2.5 \mu \mathrm{m}$ wide. Both algal and fungal filaments branched frequently.
The interior surfaces of pore walls were often beset by numerous protrusions which extended from the corallum wall into the pore space (' $c$ ' in Fig. 2B). These protrusions were mostly conical with rounded tips, and were rarely attenuated to a point. The carbonate was deposited externally by apposition, often exhibiting stromatolite-like layering (Fig. 4A). These conical protrusions were numerous (Fig. 5), reaching densities of 1000 to $15000 \mathrm{~mm}^{-2}$. They were 7 to $18 \mu \mathrm{m}[10.8 \pm 2.0$ (55)] wide at the base, and up to $20 \mu \mathrm{m}[10.73 \pm 3.28$ (26)] high.

Each cone contained a fungal hypha; however, within the region inhabited by polyps, the cones were all sealed. The surface of the skeleton in this region appeared intact when viewed under SEM (Fig. 5), indicating that the endoliths were largely confined to the interior of the skeleton and did not enter the pore space or the soft coral tissue (see also Fig. 3a in Le Campion-Alsumard et al. 1995). We examined the conical carbonate protuberances above and below the dissepiments that separated live coral tissue from evacuated pore spaces below. Immediately below the dissepiments, the cones appeared unchanged and also showed similar distribution and densities to those above the dissepiments. However, less than half a $\mathrm{mm}$ below the dissepiment, the majority of cones 


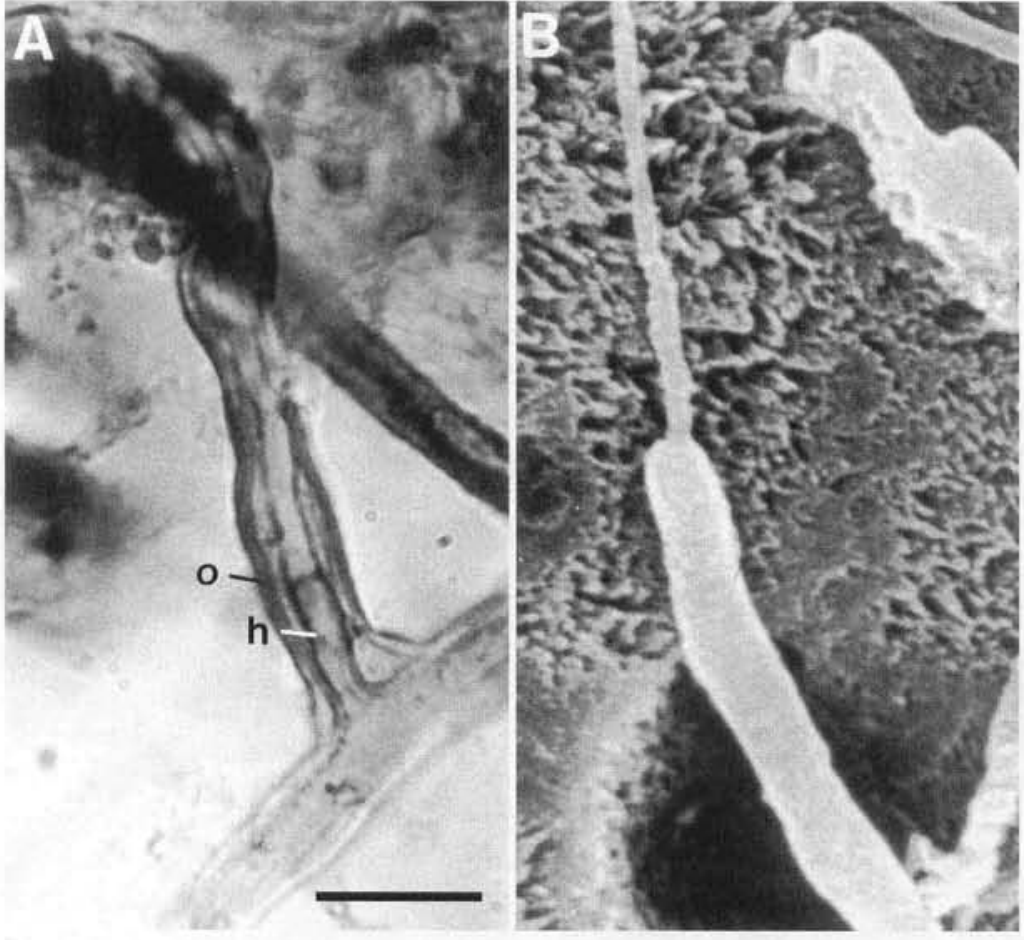

Fig. 3. Interaction between endolithic algae and fungi in Porites lobata. (A) A septate hypha (h) growing inside a filament of Ostreobium quekettii (o). The branching fungus follows the branching pattern of the algal host. Light micrograph. (B) Casts of a contact between tunnels of a fungal hypha and $O$. quekettii. SEM; same magnification; scale bar $=10 \mu \mathrm{m}$ were perforated, with fungal hyphae exiting into the pore space (Fig. 6). The immediate consequence of hyphae leaving the confinement of their boreholes was a turgescent swelling of up to $3.5[2.4 \pm 0.39(16)] \mu \mathrm{m}$ diameter (Figs. 4B, C \& 7). From that point on, the hyphae continued to grow, forming transverse septa (Fig. 4C) and maintaining a diameter of 1.2 to $2.3 \mu \mathrm{m}$ $[1.75 \pm 0.57(49)]$. The cones were composed of densely packed, slightly upward-diverging fibrous aragonite. At higher SEM magnification, the outlines of fine, submicron-size crystal faces were visible, contrasting with much larger grains of normal corallum crystal fans (Fig. 8).

Fungal hyphae within the pore space (cryptoendoliths) were mostly straight, with occasional branching (Fig. 9). The tunnels of hyphae inside the coral skeleton (euendoliths) cast in polymerizing resin were visualized by SEM following dissolution of carbonate. These hyphae curved irregularly and branched more frequently, with branches ending in depressions representing the interior of the cones (Fig. 10).

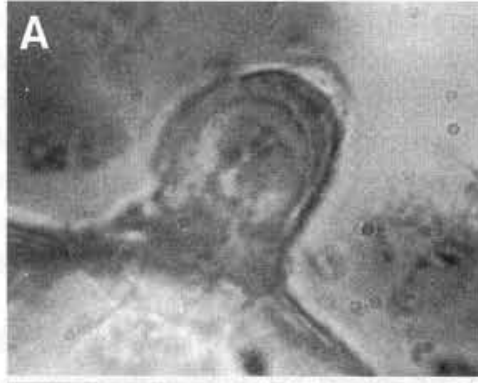

B

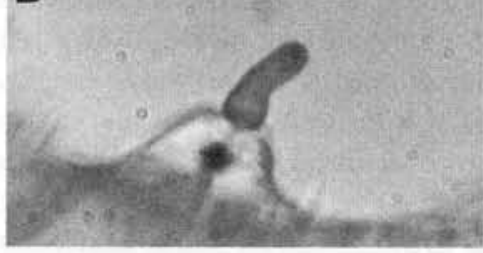

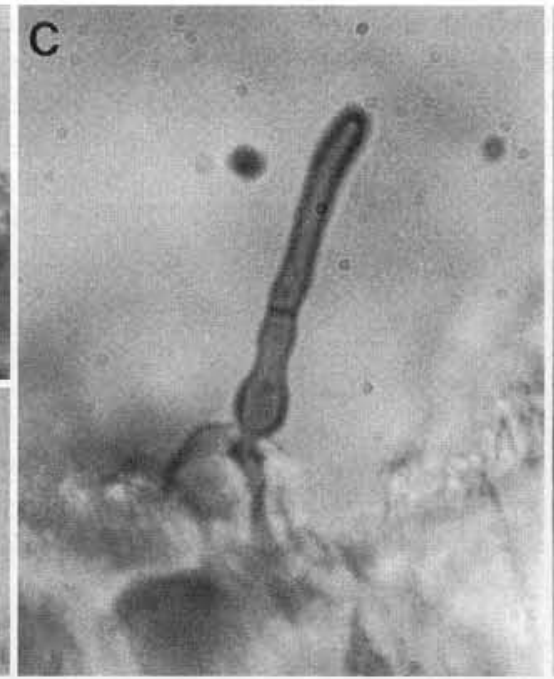

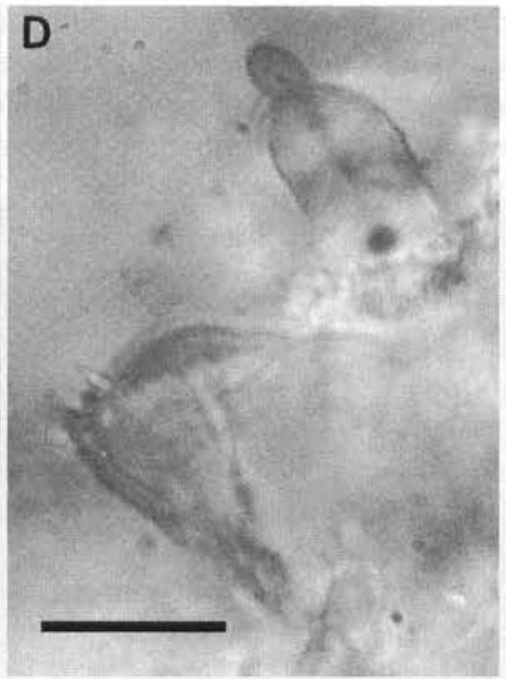

Fig. 4. Porites lobata. Calcareous cones and fungi on the pore walls of the corallum. (A) A hemispherical protuberance containing a fungal hypha in the center, growing by external apposition of layers of dense repair carbonate deposited by the coral. Dark patches left and right of the cone are osmium-stained coral tissue. (B) Fungal hypha emerging from the cone. Note the slight swelling of the hypha at the point of exit from the endolithic tunnel. (C) Formation of the first septum by the hypha upon exiting into the pore space. (D) Early diagenetic alteration of the cone; fine pointed needles appear on top of the cones by syntaxial growth of densely deposited repair aragonite. Light micrographs; same magnification; scale bar $=10 \mu \mathrm{m}$ 

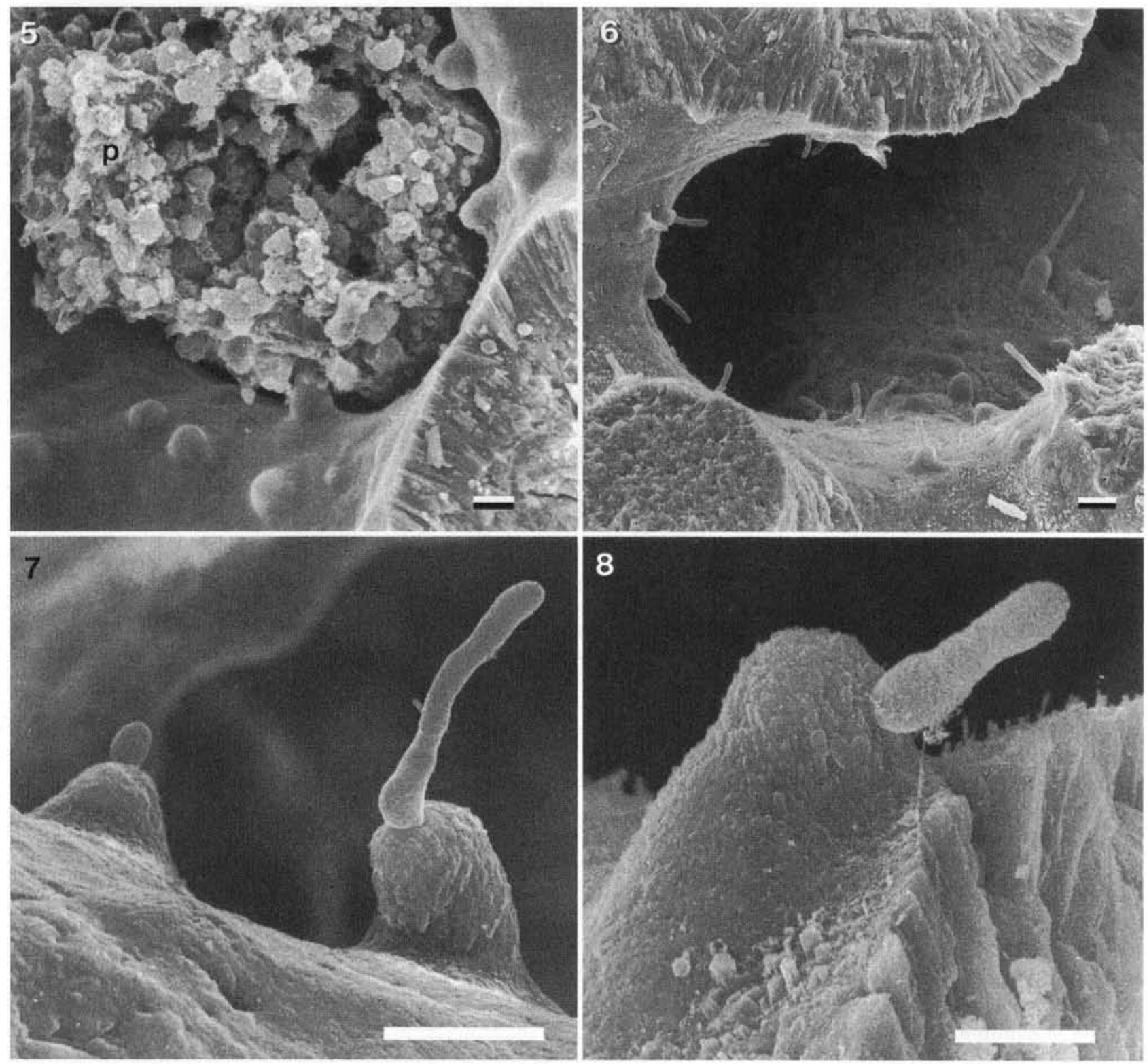

Figs, 5 to 8. Porites lobata. Calcareous protuberances (cones) on skeletal walls resulting from coral-fungus interaction in inhabited and uninhabited coral regions above and below the uppermost dissepiment. Fig. 5. Pore wall surface with numerous hemispherical to bluntly conical protuberances adjacent to polyp tissue (p). None of the cones in the picture is perforated. Scale bar $=$ $10 \mu \mathrm{m}$. Fig. 6. Walls of evacuated pore spaces below the dissepiment (ca $4 \mathrm{~mm}$ below the surface), showing perforated cones with protruding hyphae. In the absence of coral defense, fungal hyphae perforate the cones and profusely enter the pore space. Scale $\mathrm{bar}=10 \mu \mathrm{m}$. Fig. 7. Detail showing 2 cones with emerging fungal hyphae. The hyphae expand by turgescent swelling when exiting the carbonate cone. Scale bar $=10 \mu \mathrm{m}$. Fig. 8. Closer view showing structural differences of skeletal carbonate (fractured, at right) and repair carbonate (cone). The exposed crystal planes reveal the differences in grain size. SEM of critical-point-dried preparation; scale bar $=5 \mu \mathrm{m}$

Septate fungal hyphae with larger diameters were observed within the soft coral tissue, occasionally bearing conidia. Whether these fungi are identical with the endolithic ones and represent successful invaders of polyps through conical structures, or are an unrelated group, could not be established.

\section{Interpretation: dynamics of coral-fungus interaction}

The interaction between microbial euendoliths and polyps can be understood in the context of coral skeletal architecture (Fig. 1) and the rhythm of coral growth (Barnes \& Lough 1992). Skeleton formation is initiated 

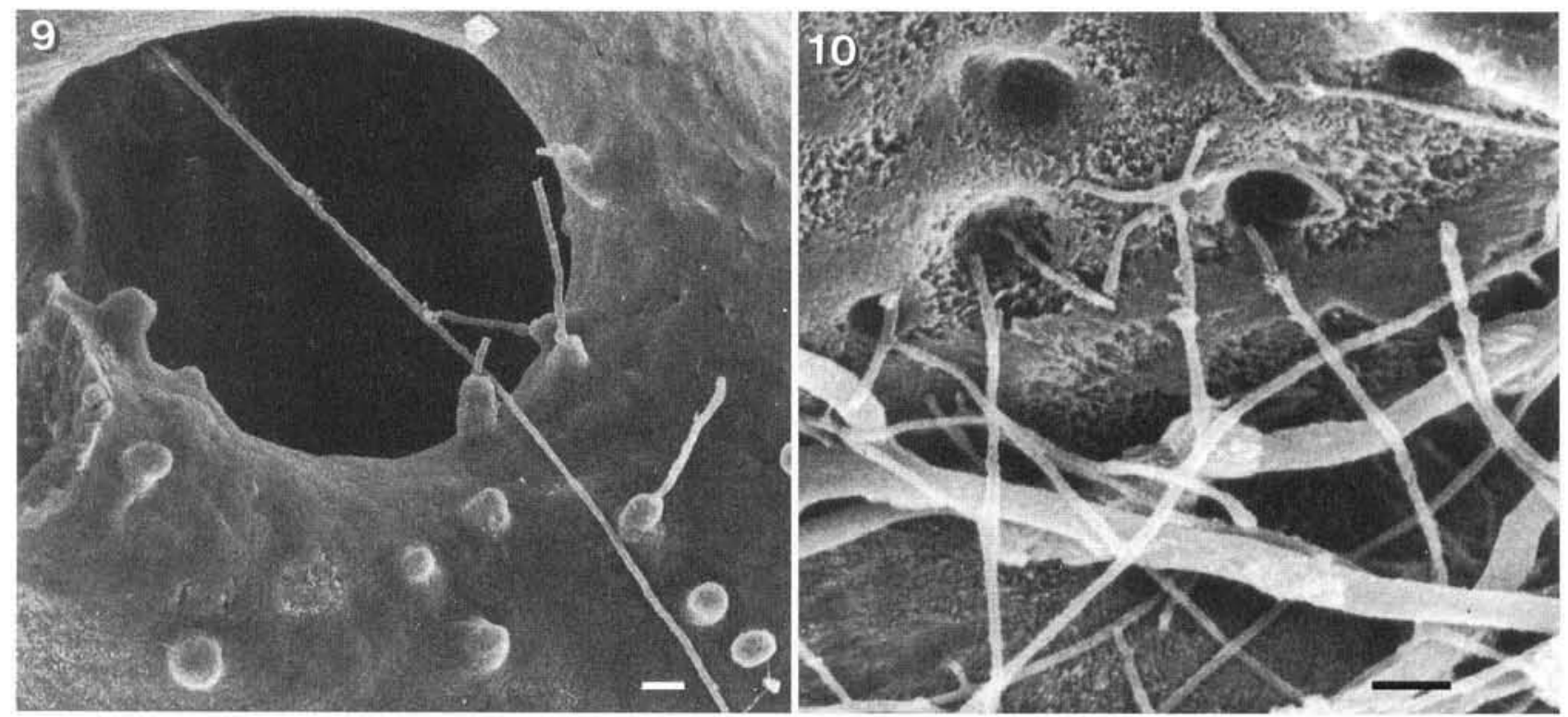

Figs. 9 \& 10. Porites lobata. Distribution of fungal hyphae in corals. Fig. 9. Growth of fungal hyphae in empty pore spaces (cryptoendoliths). SEM of critical-point-dried specimen; scale bar $=10 \mu \overline{\mathrm{m}}$. Fig. 10 . Euendolith distribution inside the carbonate substrate. The 'inside view' was produced by casting perforations in polymerizing resin, then dissolving the carbonate. Thinner filaments are tunnels of fungal hyphae ending in cones at the top. Larger ones are made by Ostreobium quekettii. Scale bar $=10 \mu \mathrm{m}$

within the polyp tissue by the formation of carbonate nucleation centers, from which aragonite crystals radiate into spherulitic aggregates called sclerodermites (Barnes 1970). Sclerodermites fuse subsequently into a skeletal network. In Porites spp. sharp, vertical spikes (pali), concentrically arranged around a central columella, form at the growing front of each polyp (Veron $\&$ Pichon 1982). They thicken by continuing carbonate apposition syntaxial with the initial sclerodermite fans, and later become laterally interconnected by horizontal bars or synapticulae (Barnes \& Lough 1993). Coral skeletogenesis and thickening proceed continuously throughout the entire area occupied by live polyps, although carbonate deposition rates vary with seasons (Barnes \& Lough 1993). As a part of this process, the polyps stretch upward, and they contract incrementally by lifting their lower end upward. Each uplift of polyps terminates with the formation of a horizontal calcified dissepiment, which separates the 'living quarters' of the polyps from the underlying old, now uninhabited pore spaces.

Interactions between endoliths and polyps take place only within the region inhabited by polyps, but the evidence of this interaction remains preserved in the skeleton below in the form of calcareous cones. Small septate endolithic fungi, which apparently parasitize endolithic algae (Fig. 3), also attack the polyps. The polyps are evidently able to detect the approach of the fungus and to respond in a defensive manner. The coral defense involves intensive carbonate nucleation around the site of fungal penetration which results in formation of a layer of dense, fine-grained repair carbonate (Fig. 17, stages 1 and 2). This deposit, however, seems to be no more of an obstacle to fungal penetration than normal coral skeleton, so that fungal penetration continues, and the process must be repeated, resulting in layered growth of the protuberance (Fig. 4A \& Fig. 17, stage 3). The steepness of the cone is determined by the balance between fungal penetration and deposition rates of the repair carbonate. Higher deposition rates keep the cones broadly hemispherical, whereas higher penetration rates result in a narrowing of the depositional field around the hypha, ending in a point. Each cone is, therefore, a site of confrontation between the fungus and the polyp. The fungal penetration and polyp repair rates are roughly balanced, with a gradual 'retreat' of the polyp tissue occurring, accompanied by the growth of the cone (Fig. 5). The frequency of fungal attack and the ability of the polyps to detect and defend against it, as illustrated by the number of cones on the pore walls, implies a parasitic rather than saprophytic role of fungi in corals.

The polyps ultimately escape the invasion of endolithic fungi by their upward displacement and by sealing off the evacuated compartment with a dissepi- 

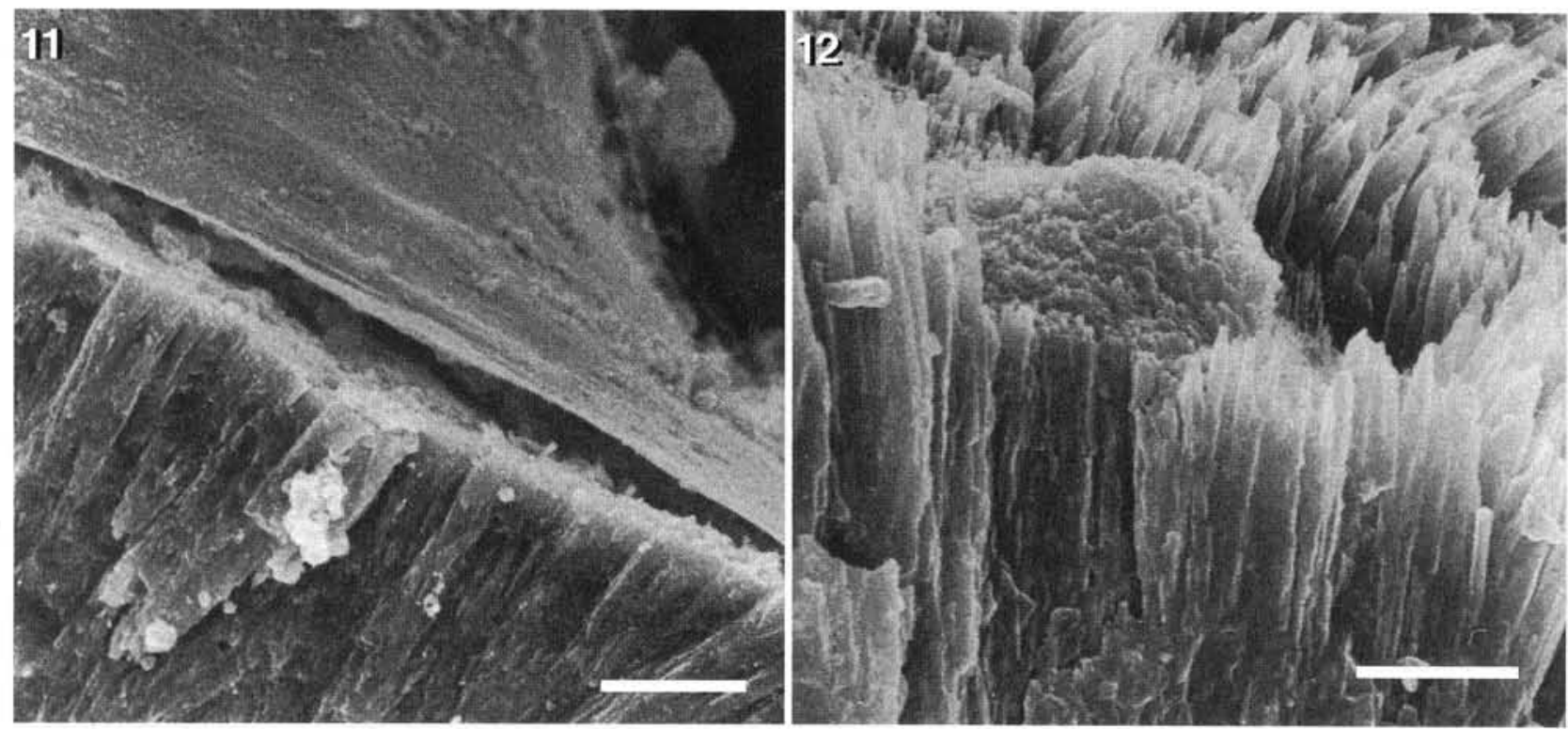

Figs. 11 \& 12. Porites lobata. Diagenetic syntaxial growth of skeletal carbonate. Fig. 11. Smooth-planed skeletal wall, formed in contact with the calycoblastic polyp epithelium, is comprised of 'truncated' (across the c-axis) aragonite crystals. Scale bar = $10 \mu \mathrm{m}$. Fig. 12. Diagenetic syntaxial crystal growth continuing into the pore space, located deeper within the coral skeleton than the structure shown in Fig. 11. Fungal protuberances surrounded by acicular aragonite are characterized by much smoother surfaces. Scale bar $=5 \mu \mathrm{m}$

ment. Deprived of resistance, the fungal hyphae emerge from the cones, 'running into opened doors' (Figs. 6 to 10; Fig. 17, stage 4). Their success, however, is apparently short-lived: turgescent hyphae are found only in the uppermost pore spaces; deeper in the coral skeleton they deteriorate, leaving only the cones as evidence of their past interaction with polyps.

\section{Epilogue: fungi and coral diagenesis}

Skeletogenesis in corals is most strongly subject to biological control at the outset of the process, when the specific location of sclerodermite nucleation centers is determined, and at the end of the mineralization process, when skeleton formation finishes upon contact with the calycoblastic tissue of the polyps (Johnston 1980). Finished pore wall is smooth, lined by structural aragonite crystals that are 'truncated' across their c-axes, ending with flat, 'planed off' (Constantz 1986a, b) crystal faces (Fig. 11).

Diagenesis of coral skeleton begins following the upward withdrawal of coral tissue. Additional precipitation of calcium carbonate originates within structural voids from carbonate-supersaturated pore waters. This occurs by syntaxial continuation of skeletal crystal growth (Pätzold 1988). The crystals lining pore walls continue to grow uninhibited along their c-axes
(Fig. 12), arranged in groups that reveal the fascicular organization of the skeleton (Le Tissier 1990). In contrast, areas affected by fungal attack remain smooth and appear darker in scanning electron micrographs (Fig. 13).

The tips of the diagenetically altered skeletal crystals initially inherit their truncated prismatic morphology (Fig. 14, periphery), later assuming the pointed crystal morphology of acicular aragonite, whereas the cones remain unchanged, each comprised of and surrounded by smooth repair carbonate (Fig. 14, center). Apparently, the repair carbonate resists diagenetic crystal growth longer than normal skeletal carbonate.

Diagenetic syntaxial growth ultimately resumes on smooth areas of the repair carbonate as well, but this growth is characterized by the generation of fine, sharply pointed aragonitic needles (Fig. 15). The presence of a still-turgescent hypha exiting from a cone surrounded by newly grown fine acicular crystals (Fig. 16) implies a very early onset of diagenesis in coral skeletons.

The process of fungal-coral interaction can be summarized as follows (Fig. 17, stages 1 to 5). When an endolithic fungal hypha approaches the skeletal surface of an inhabited pore (stage 1), it is detected by the polyp, which responds by initiating carbonate nucleation. A coating of dense repair carbonate is precipitated around the point of hyphal attack (stage 2). As 


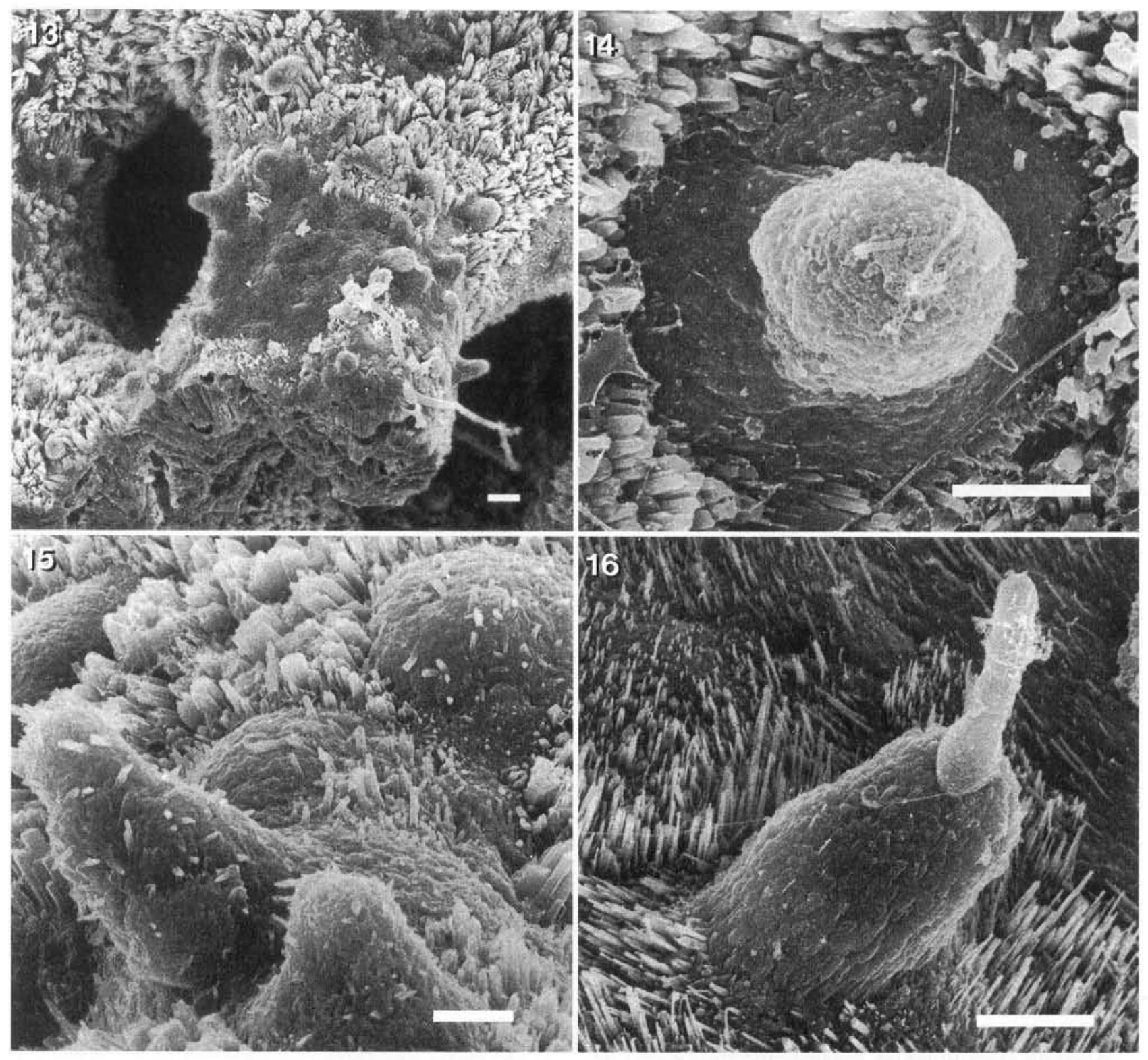

Figs. 13 to 16. Porites lobata. Diagenetic syntaxial growth on repair carbonate. Fig. 13. View of the interior of a skeletal pore showing bundles of diagenetically grown skeletal aragonite, with smooth areas of repair aragonite (darker region) deposited in response to fungal attack. SEM of a bleached skeleton; scale bar $=10 \mu \mathrm{m}$. Fig. 14. Top view of a fungal cone surrounded by a 'halo' of dense repair carbonate, where syntaxial crystal growth is delayed. Syntaxial growth of normal skeletal carbonate is seen peripheral to the smooth repair carbonate. Scale bar $=5 \mu \mathrm{m}$. Fig. 15. Side view of a group of fungal cones beset with fine aragonite needles starting to grow syntaxially from densely deposited repair carbonate. Scale bar $=5 \mu \mathrm{m}$. Fig. 16 . A cone with protruding fungal hypha surrounded by fields of fine aragonitic needles syntaxially growing from an area of repair carbonate. Scale bar $=5 \mu \mathrm{m}$

the hypha continues to penetrate the repair coating, the process is repeated by adding more carbonate layers (stage 3), resulting in growth of a calcareous protuberance or cone. Following upward withdrawal of polyp tissue, fungal hyphae successfully penetrate the repair carbonate, exit the skeleton and enter the now emptied pore space (stage 4). The patterns of diagenetic carbonate precipitation that follow are different for the original (intact) pore wall surfaces and for the repair carbonate (stage 5 ), leaving a preserved record of fungal boring intensity during the period of active skeletogenesis. 


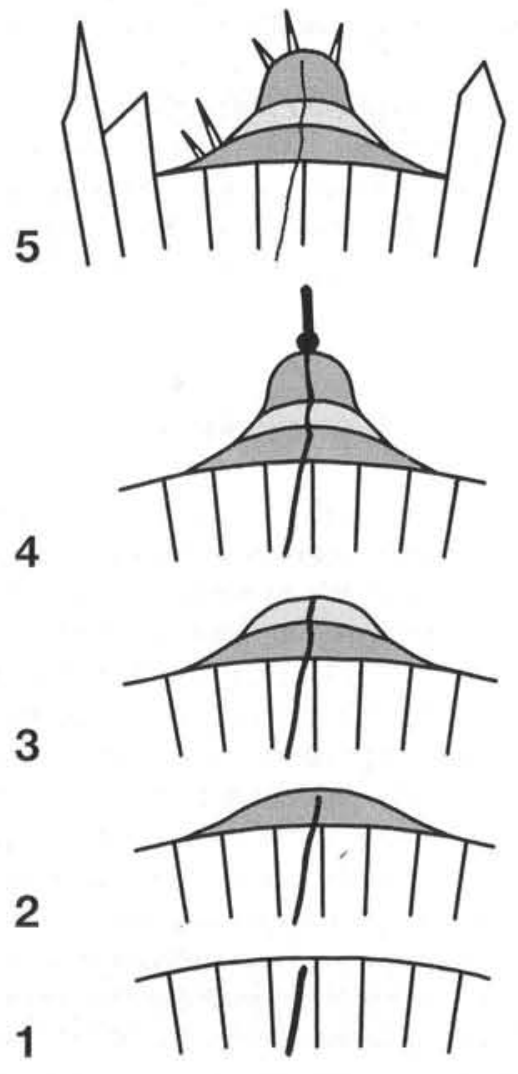

Fig. 17. Schematic presentation of the interaction between endolithic fungi and Porites lobata, and its diagenetic consequences. Stages 1 to 3 : fungal penetration, and subsequent coral response by deposition of layers of repair carbonate. Stage 4: exiting of fungal hyphae into pore space following upward evacuation of coral tissue. Turgescent swelling accompanies release from confinement by the skeleton. Stage 5 : difference in diagenetic syntaxial crystal growth between intact pore wall areas (large crystals) and areas of repair carbonate (small crystals)

The progression of early diagenesis varies considerably from one pore space to the next, resulting in discrepant crystal lengths in neighboring pores. Acicular aragonite crystals up to $50 \mu \mathrm{m}$ long, virtually filling the pore space, are found only $25 \mathrm{~mm}$ below the growing coral front. At the growth rates measured for the Porites lobata in Moorea, this diagenetic stage is achieved within 2 to $3 \mathrm{yr}$.

\section{DISCUSSION}

The present study established the abundant presence and autochthonous growth of fungi in Porites lobata. Septate fungal hyphae were found to be common in corals and assumed the following ecological roles: as euendoliths they penetrate coral skeleton; as cryptoendoliths they reside within pore spaces; and as endophytes they grow inside filaments of endolithic algae. In addition, fungi were found inside the soft coral tissue, where they produced conidia in situ. A successful isolation and culturing of higher, ascomycotic and basidiomycotic fungi from the skeletons of Atlantic and Pacific hermatypic corals (Kendrick et al. 1982) permitted the first identification of fungal genera and species that were likely candidates for the common coral borers, and identification of other autochthonous fungi, but a direct relationship between these isolates and their natural niches within corals could not be established. Kendrick et al. (1982) reported the growth of 20 taxa belonging to 12 genera and representing 18 species of omnivorous, saprobic, dicaryomicotan anamorphous fungi. However, these fungi produced conidia only in culture.

The present paper disclosed that endolithic fungi elicit defensive behavior on the part of the coral, indicating a parasitic rather than saprophytic relationship. Endolithic fungi also attack and enter filaments of endolithic algae; however, the possibility that fungal infection took place after the death of the alga could not be excluded in the present study.

Formation of conical carbonate structures has been reported earlier for species of the corals Colpophyllia and Monastrea by Scherer (1974), who observed 25 to $35 \mu \mathrm{m}$ wide and 30 to $50 \mu \mathrm{m}$ high cones rising from pore walls. Those structures, about twice the size of the cones reported in this paper, were attributed to endolithic algae rather than fungi. Scherer speculated on the mechanisms that might have caused precipitation by algae, but did not consider that the deposition might be a response of the coral to endolith action.

The present paper demonstrates that the formation of carbonate cones in conjunction with fungal attack takes place only within the region inhabited by corals. This deposition involves new crystal nucleation and is analogous to pearl formation in mollusks, where the animal responds to, and isolates, the foreign body by carbonate deposition. The present paper also shows that the cones grow externally by apposition, pointing to the surrounding polyp tissue as the source of added carbonate. Any bioerosional damage that occurs subsequent to the upward displacement of polyps remains unchallenged. In that sense, the skeletal and the repair carbonate are virtually syndepositional.

Constantz (1986a) recognized the existence of skeletal nucleation on corallum surfaces in addition to that initiating sclerodermite centers. He described 'spines, dentations, and granulations', but considered these to be part of normal skeletal growth in corals, associated with intersections of trabecular axes. His illustrations (Fig. 2E, F), however, show cones similar in shape and 
size to those formed in response to fungal attack as demonstrated in the present work.

A response of gorgonian corals to penetration of green algae that triggers proliferation of organic skeletal tissue and tumor formation has been reported by Morse et al. (1977) and was later studied by Goldberg \& Makemson (1981) and Goldberg et al. (1984). Increased calcification accompanied this response, resulting in a higher density of carbonate spicules inside tumors.

The present study demonstrates that differences in primary skeletal crystallization patterns between intact skeletal carbonate and the repair carbonate associated with fungi and cone formation persist through diagenetic alterations. Intact pore walls and surfaces of repair carbonate are both subject to syntaxial growth of diagenetic carbonate, but the results are fibrous crystals of vastly disparate sizes. Diagenetic precipitation on intact pore walls produces syntaxial growth of large acicular aragonite crystals that conforms with the mineralogy of the original spherulitic sclerodermite units of coral skeleton (Constantz 1986b, Pätzold 1988). We observed similarly syntaxial diagenetic crystal growth on dense repair carbonate. However, the latter occurred after a delay and resulted in the formation of much finer aragonitic needles (Figs. 15 \& 16; Fig. 2F in Constantz 1986b). We agree with Constantz' conclusion that these fine fibrous aragonite crystals, shown to emanate from the tips of the cones, are abiotically controlled, i.e. diagenetic in origin; they reflect, however, past biological interactions.

Pätzold (1988) reported advanced diagenetic carbonate precipitation localized within skeletal voids, which were often filled with large aragonite needles exceeding $50 \mu \mathrm{m}$ length. These occurred under marine conditions 80 to $100 \mathrm{yr}$ after the death of the coral. Advanced diagenetic alteration occurring within 10 to 12 yr after coral death was reported by Potthast (1992). We could demonstrate similarly advanced stages of diagenesis in isolated intraskeletal microenvironments, that developed within 2 to $3 \mathrm{yr}$ following skeletogenesis. No Mg-calcite coating (Pätzold 1988) was observed in our samples, suggesting a later diagenetic origin of this mineral phase (see Hook et al. 1984). Uneven diagenetic rates in coral skeletal pores seem to be the norm. As Porites constructs its skeleton 'floor by floor' (Barnes \& Lough 1993) it creates compartments, which act as separate microenvironments of diagenesis. Carbonate precipitation that ensues after the evacuation of the pores by the polyps may, therefore, proceed at locally different rates, resulting in uneven changes in corallum density. Microbioerosion of coral skeleton, on the other hand, may act in the opposite direction, by increasing the permeability of skeletal walls. These facts need to be considered in interpreta- tions of stable isotope and trace metal distribution in corals.

Pätzold (1988) reported that 'infestation of the coral by boring algae initiates very early carbonate cementation of the intraskeletal voids'. We observed intensive and very early initiation of fibrous cement in pore spaces that was definitely not associated with algal borings.

\section{CONCLUSION}

Under normal growth conditions a balanced hostparasite equilibrium between corals and fungi may become established. We hypothesize, however, that a disturbance of such equilibrium, caused for example by environmental stress, may result in an increase in the frequency of fungal attack. It is conceivable that, like algae, endolithic fungi represent normal inhabitants of coral reefs, inflicting little or no damage on healthy corals. However, like opportunistic pathogens in humans, these fungi (and other bioeroding organisms) may become an important factor in damaging corals weakened by environmental stress. The distribution of compact repair aragonite within coral skeleton which forms in response to fungal attack may, therefore, be a good indicator of overall coral health at the time of skeleton formation.

Acknowledgements. This work was supported by grant 'Récifs coralliens' from INSU/ORSTOM (AIP), by the National Associate Professor Program of the University of Aix-Marseille, and by grant PICS 77 (French-Australian Cooperation).

\section{LLTERATURE CITED}

Antonius, A. (1981a). Coral reef pathology: a review. Proc. 4th Int. Coral Reef Symp. 2: 3-6

Antonius, A. (1981b). The band diseases in coral reefs. Proc. 4th Int. Coral Reef Symp. 2: 7-14

Bak, R. P. M., Laane, W. P. M. (1987). Annual black bands in skeletons of reef corals (Scleractinia). Mar. Ecol. Prog. Ser. 38: $169-175$

Barnes, D. J. (1970). Coral skeleton: an explanation of their growth and structure. Science 170: 1305-1308

Barnes, D. J., Lough, J. M. (1992). Systematic variations in the depth of skeleton occupied by coral tissue in massive colonies of Porites from the Great Barrier Reef. J. exp. mar. Biol. Ecol. 159: 113-128

Barnes, D. J., Lough, J. M. (1993). On the nature and causes of density banding in massive coral skeletons. J. exp. mar. Biol. Ecol. 167: 91-108

Bornet, E., Flahaut, C. (1889). Sur quelques plantes vivant dans le test calcaire des mollusques. Soc. Bot. France, Bull. 36: $147-176$

Chalker, B. E. (1983). Calcification by corals and other animals on the reef. In: Barnes, D. J. (ed.) Perspectives on coral reefs. Australian Institute of Marine Science, by Brian Clouston Publ., Canberra, p. 29-45 
Constantz, B. R. (1986a). Coral skeleton construction: a physiochemically dominated process. Palaios 1: 152-157

Constantz, B. R. (1986b). The primary surface area of corals and variations in their susceptibility to diagenesis. In: Schroeder, J. H., Purser, B. (eds.) Reef diagenesis. Springer-Verlag, New York, p. 53-76

Goldberg, W. M., Makemson, J. C. (1981). Description of a tumorous condition in a gorgonian coral associated with a filamentous green alga. Proc. 4 th Int. Coral Reef Symp. 2: 685-697

Goldberg, W. M., Makemson, J. C., Colley, S. B. (1984). Entocladia endozoica sp. nov., a pathogenic chlorophyte: structure, life history, physiology, and effect on its coral host. Biol. Bull. 166: 368-383

Golubic, S., Brent, G., Le Campion, T. (1970). Scanning electron microscopy of endolithic algae and fungi using a multipurpose casting-embedding technique. Lethaia 3 : 203-209

Golubic, S., Friedmann, I., Schneider, J. (1981). The lithobiontic ecological niche, with special reference to microorganisms. J. sedim. Petrol. 51: 475-478

Halldal, P. (1968). Photosynthetic capacities and photosynthetic action spectra of endozoic algae of the massive coral Favia. Biol. Bull. 134: 411-424

Hook, J. E., Golubic, S. (1993). Microbial shell destruction in deep-sea mussels, Florida Escarpment. P.S.Z.N. I: Mar. Ecol. 14: 81-89

Hook, J. E., Golubic, S., Milliman, J. D. (1984). Micritic cement in microborings is not necessarily a shallow-water indicator. J. sedim. Petrol. 54: 425-431

Johnston, I. S. (1980). The ultrastructure of skeletogenesis in hermatypic corals. Int. Rev. Cytol. 67: 171-214

Kendrick, B., Risk, M. J., Michaelides, J., Bergman, K. (1982). Amphibious microborers: bioeroding fungi isolated from live corals. Bull. mar. Sci. 32: 862-867

Le Campion-Alsumard, T., Golubic, S., Hutchings, P. (1995). Microbial endoliths in skeletons of live and dead corals: Porites lobata (Moorea, French Polynesia). Mar. Ecol. Prog. Ser. 117: 149-157

Le Tissier, M. D'A. A. (1990). The ultrastructure of the skele-

This article was submitted to the editor ton and skeletogenic tissues of the temperate coral Caryophyllia smithii. J. mar. biol. Ass. U.K. 70: 295-310

Le Tissier, M. D'A. A. (1991). The nature of the skeleton and skeletogenous tissues in the Cnidaria. Hydrobiologia 216/217: 397-402

Lukas, K. J. (1974), Two species of the chlorophyte genus Ostreobium from skeletons of Atlantic and Caribbean reef corals. J. Phycol. 10: 331-335

Morse, D. E., Morse, A. N. C., Duncan, H. (1977). Algal 'tumors' in the Caribbean sea fan, Gorgonia ventalina. Proc. 3rd Int. Coral Reef Symp. 1: 623-629

Pätzold, J. (1988). The effect of early lithification on the stable oxygen and carbon isotopic composition of Porites lobata. Proc. 6th Int. Coral Reef Symp. 3: 559-564

Pearse, V. B., Muscatine, L. (1971). Role of symbiotic algae (zooxanthellae) in coral calcification. Biol. Bull. 141: $350-363$

Porter, D., Lingle, W. L. (1992), Endolithic thraustochytrid marine fungi from planted shell fragments. Mycologia 84: 289-299

Potthast, I. (1992). Short-term progressive early diagenesis in density bands of recent corals: Porites colonies, Mauritius Island, Indian Ocean. Facies 27: 25-27

Pulicek, M. (1983). Patterns of mollusk shell biodegradation in bathyal and abyssal sediments. J. Mollusc. Stud. 12A: 136-141

Raghukumar, C., Raghukumar, S. (1991). Fungal invasion of massive corals. P.S.Z.N. I: Mar. Ecol. 12: 251-260

Rützler, K., Santavy, D. L., Antonius, A. (1983). The black band disease of Atlantic reef corals. P.S.Z.N. I: Mar. Ecol. 4: 329-358

Scherer, M. (1974). The influence of two endolithic microorganisms on the diagenesis of recent coral skeletons. N. Jb. Geol. Palaeontol. Monatsh. 9: 557-566

Shashar, N., Stambler, N. (1992). Endolithic algae within corals - life in an extreme environment. J. exp. mar. Biol. Ecol. 163: 277-286

Veron, J. E. N., Pichon, M. (1982). Scleractinia of Eastern Australia, Part 4. Australian Institute of Marine Science and Australian National University Press, Canberra

Manuscript first received: July 11, 1994

Revised version accepted: October 4, 1994 